\title{
Antibiotics usage, how well we know it? KAP survey among the dentist population in Mumbai
}

\author{
Amisha N. Parekh ${ }^{3 *}$, Karthik Balasubramanian', Purvi Bhate ${ }^{2}$, Dheeraj D. Kalra ${ }^{2}$
}

\author{
${ }^{1}$ Department of Periodontology and Implantology, ${ }^{2}$ Department of Public Health Dentistry, ${ }^{3}$ YMT Dental College and \\ Hospital, Kharghar, Navi Mumbai, Maharashtra, India
}

Received: 12 September 2020

Accepted: 12 October 2020

\author{
*Correspondence: \\ Dr. Amisha N. Parekh, \\ Email: anp2988@yahoo.com
}

Copyright: $\odot$ the author(s), publisher and licensee Medip Academy. This is an open-access article distributed under the terms of the Creative Commons Attribution Non-Commercial License, which permits unrestricted non-commercial use, distribution, and reproduction in any medium, provided the original work is properly cited.

\begin{abstract}
Background: There is a rising concern for antibiotic resistance worldwide, the primary cause of which is overuse and misuse. This study primarily aimed at assessing the knowledge of dental practitioners regarding the current guidelines on use of antibiotics and to identify the shortcomings if any.

Methods: Present study was a cross-sectional questionnaire-based study conducted amongst 450 dental practitioners across Mumbai with the help of a self-designed questionnaire. The data was entered into excel sheets and appropriate statistical analysis was done with chi-square test using SPSS version 20.

Results: The present study had a response rate of $95 \%$. For the total percentage of patients examined each day that required systemic antibiotics, 36.9\% (153) dentists answered $0-5 \%$, followed by $25.3 \%$ (105) answered $10-15 \%$. $76.1 \%$ (316) dentists came across patients who had self-prescribed antibiotics. 66\% (274) dentists had never advised an antibiotic sensitivity/ culture test for their patients. 51.3\% (213) dentists came across patients who did not respond to antibiotics. $87.2 \%$ (363) dentists were not aware about the 'AWaRe' classification of antibiotics given by WHO. 93.3\% (383) dentists did not know about antimicrobial stewardship concept.

Conclusions: The present study reflected antibiotic overuse and misuse to a certain extent by dental practitioners across Mumbai. Most dentists were unaware about 'AWaRe' classification and antimicrobial stewardship. Patient education on ill effects of self-prescription of antibiotics, identification of traits of antibiotic resistance and antibiotic culture tests needs to be prioritized by dentists.
\end{abstract}

Keywords: Antimicrobial stewardship, Antibiotic resistance, Antibiotics survey, AWaRe, Dental practitioners

\section{INTRODUCTION}

Antimicrobial resistant superbugs have become a reality of the present age and nosocomial infections by these organisms seem to indicate the alarming levels of antibiotic resistance that has run rampant in countries of all income levels. Thereby rendering common diseases untreatable and making life saving procedures riskier to perform. At-least 700,000 deaths have been reported globally as a result of drug resistance in a single year out of which 230,000 have resulted from multi-drug resistant tuberculosis. A grim figure which can become even more grim considering a prediction of 10 million deaths globally per year by 2050 , which definitely makes drug resistance the scourge of medical profession unless swift and sustained actions are not ensued upon. ${ }^{1}$ Around 2.4 million people could die in high-income countries between 2015 and 2050 without a sustained effort to contain antimicrobial resistance. ${ }^{1}$ Globally numerous strains of Staphylococcus aureus have started to exhibit resistance to all the medically important antibiotics which even include vancomycin and methicillin resistant 
Staphylococcus aureus has become one of the most feared and frequent nosocomial pathogen. ${ }^{2}$

The use of systemic antibiotics has been a common part of the dental practice and has escalated to a great extent in the past two decades. The indiscriminate use of antibiotics runs the risk of producing superbugs which can render fatal infections when the patient is susceptible. The lacuna of solid scientific evidence stating the clinical situations that require systemic delivery of antibiotics tend to accentuate the constraint and limit the restraint on part of the dental practitioner to prescribe antibiotics. Clinical situations that require antibiotic therapy on an empirical basis are limited and include oral infection with evidence of systemic spread such as lymphadenopathy and trismus. $^{3}$ Endodontic conditions like reversible pulpitis, irreversible pulpitis with moderate/severe preoperative symptoms with/without apical periodontitis do not warrant antibiotic coverage. Despite these facts, there has been a tendency to prescribe antibiotics for this conditions. $^{4}$

The World health assembly's endorsement of the global action plan on antimicrobial resistance (AMR) in May 2015 and the political declaration of the high-level meeting of the general assembly on AMR in September 2017 have recognized AMR as a global threat to public health. ${ }^{5}$

\section{METHODS}

The present cross-sectional survey was conducted in February 2020, involving the dentists across Mumbai (Maharashtra, India). This study was conducted with the aim of assessing the knowledge, attitude and practice (KAP) of dental practitioners regarding the use of antibiotics. Inclusion criteria for the current study were dental practitioners having a minimum of bachelor of dental surgery degree. Practitioners who were unwilling to participate were excluded from the same.

A self designed questionnaire survey was designed to assess the knowledge of dental practitioners regarding the guidelines for the use of antibiotics. The survey questionnaire was constructed after thorough review of literature ${ }^{3,5-9}$. The questions were customized as to fit into the criteria of the present study. The questionnaire was content and face validated and was also pilot surveyed. It contained two parts, i.e., part A had demographic details and part B had questionnaire proper with 14 questions and 5 sub questions which were presented as 6 multiple choice questions, 10 close and 3 open ended questions. A sample size of around 450 dental practitioners was surveyed across Mumbai. The questionnaire was hand delivered and collected after dual follow up. The data was entered into excel sheets and appropriate statistical analysis was done with chi-square test using SPSS version 20 .
The above sample size of was determined using the estimates from the parent article and using a single proportion formula mentioned below; ${ }^{10}$

$$
n=\frac{1.96^{2} p(1-p)(D E F F)}{d^{2}}
$$

Where $\mathrm{p}=$ estimate of the expected proportion and $\mathrm{d}=$ desired level of absolute precision, assuming the current error prevalence/event rate to be atleast $50 \%$.

\section{RESULTS}

In the present study, out of the 450 questionnaires delivered to dental practitioners, 430 were returned back corresponding to response rate of $95 \%$, which were then screened for missing data and 15 were excluded leading to a final count of 415 . Among 415 dentists, 55.2\% (229) were females. 56.1\% (233) were aged between 20-29 years, followed by $30.1 \%$ (125) between 30-39 years. $79.3 \%$ (329) were post graduates in dental surgery (MDS). $88.9 \%$ (369) had their practice located in urban area. $57.3 \%$ (238) had institutional practice type followed by $26 \%$ (108) had mixed practice type (both private and institutional). $53.3 \%$ (221) of the dentists had an experience of $0-5$ years and $48.4 \%$ (201) participated in $\mathrm{CDE}$ programs within the last one year (Table 1). For the total percentage of patients examined each day that required systemic antibiotics, $36.9 \%$ (153) dentists in this study answered $0-5 \%$, followed by $25.3 \%$ (105) dentists who answered $10-15 \%$, followed by $21.2 \%$ (88) dentists who answered $5-10 \%$. $43.7 \%$ (412) dentists preferred to give amoxicillin followed by metronidazole $32.1 \%$ (302). A significant association was found for question 2 with specialization $(\mathrm{p}=0.001)$ (Figure 1).

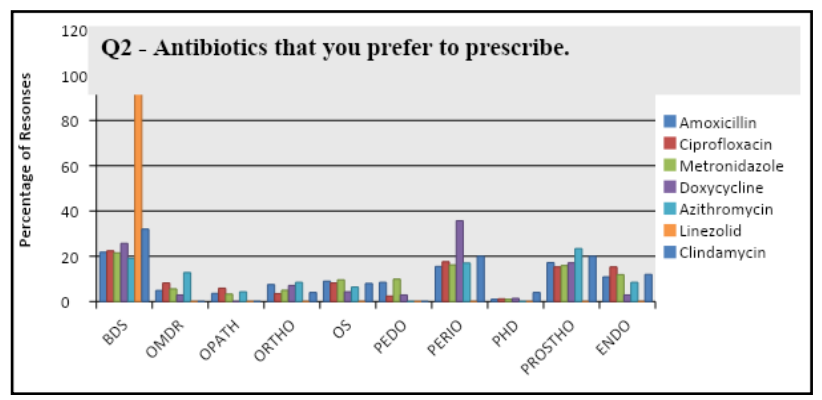

Figure 1: Percentage distribution of preference for prescription of antibiotics by the respondents.

Maximum number of dentists preferred to prescribe antibiotics for facial swelling due to dental related causes $17.3 \%$ (400), followed by dentoalveolar abscess $13.9 \%$ (321), followed by facial cellulitis $12.9 \%$ (299), followed by replantation after avulsion $11.5 \%$ (265). When given a situation of a young permanent tooth which had irreversible pulpitis, maximum dentists $40.6 \%$ (288) preferred to prescribe antibiotics under the conditions of pain with swelling, fever and lymph node involvement. 
$79.8 \%$ (331) dentists in this study believed in the use of prophylactic antibiotics before surgery. Majority of them preferred to prescribe prophylactic antibiotics for patients with previous history of infective endocarditis $19.6 \%$, followed by cardiac transplant after valvular damage $15.1 \%$, followed by uncontrolled diabetes mellitus $14.7 \%$, followed by immunocompromised patients $14.6 \%$. With question (6a) a significant association was found between age $(p=0.001)$ qualification $(p=0.003)$; specialization $(\mathrm{p}=0.001)$ and years in profession $(\mathrm{p}=$ 0.001) (Figure 2).

\begin{tabular}{|c|c|c|}
\hline & 0 & $20 \quad 40 \quad 60 \quad 80$ \\
\hline & 100 \\
No reply & 1.6 & \\
Any other & 2.1 & \\
Rheumatoid arthritis & 4.8 & \\
Uncontrolled... & 14.7 \\
Immunocompromise... & 14.6 \\
Joint replacement & 4.9 \\
Immunocompromise... & 13.3 \\
Cyanotic heart disease & 7.6 \\
Cardiac transplant... & 15.1 \\
Previous history of... & 19.6 \\
Patient with delayed... & 1.7 \\
Q6a: Conditions in which & Percentage of responses \\
prophalyatic antibiotics was used \\
\hline
\end{tabular}

Figure 2: Percentage distribution of conditions in which the respondents prescribed prophylactic antibiotics.

$76.6 \%$ of the dentists believed in beginning the prophylactic antibiotic course 1-3 days prior. Question (6b) had significant association with qualification $(\mathrm{p}=0.002)$; specialization $(\mathrm{p}=0.017)$ and years in profession $(\mathrm{p}=0.033)$ (Figure 3$)$.

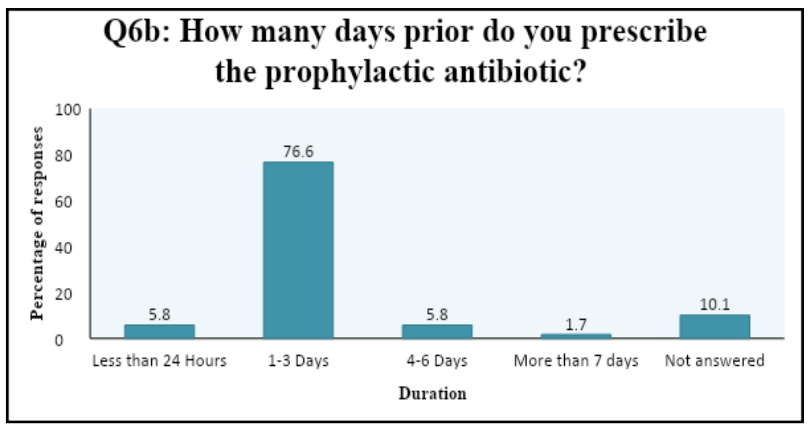

Figure 3: Percentage distribution of number of days prior to which the respondents prescribed the prophylactic dose.

$76.1 \%$ (316) dentists in this study had come across patients who had self-prescribed antibiotics. 66\% (274) dentists had never advised an antibiotic sensitivity/ culture test for their patients. $51.3 \%$ (213) dentists came across patients who did not respond to antibiotics (undergone resistance to that antibiotic). 58.6\% (243) were doing a timely check for new guidelines or any updates on existing guidelines and a significant association was found for this question (question 10a) with qualification $(\mathrm{p}=0.001)$. Out of the total respondents for this question who answered yes, $82.2 \%$ (207) were MDS and $14.8 \%$ (36) were BDS. Maximum dentists followed AAPD guidelines $16.8 \%$, followed by WHO guidelines $16 \%$, followed by AHA guidelines $12.6 \%$, followed by AAE guidelines $10.1 \%$ (Figure 4). $87.2 \%$ (363) dentists in the present study were not aware about the 'AWaRe' (access, watch, reserve) classification of antibiotics given by WHO. Out of all the respondents for question $11 \mathrm{~b}$ (categorizing the drugs according to 'AWaRE' classification by WHO) maximum dentists have categorized doxycycline as access $5.9 \%$, polymyxin $\mathrm{B}$ as reserve $4.1 \%$, vancomycin as watch $4.1 \%$, amoxicillin as access $11.5 \%$, azithromycin as access $4.5 \%$, ciprofloxacin as access as well as watch $5.6 \%$, linezolid as reserve $3.7 \%$, clindamycin as both access and watch $2.6 \%$, ceftazidime+avibactam as reserve $4.5 \%$, meropenem as reserve $4.1 \%$ and metronidazole as access $8.6 \%$ (Figure 5). 93.3\% (383) dentists in this study were unaware about the antimicrobial stewardship' concept introduced by WHO. $82.4 \%$ (342) dentists believed that the packet of antibiotics should include its susceptibility towards pathogens. $81.9 \%$ (340) dentists had not attended any CDE programs arranged for antibiotic abuse or antibiotic resistance recently (Table 2).

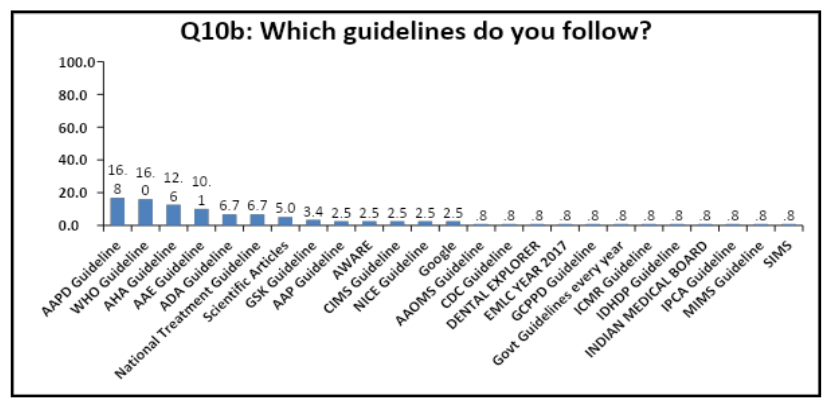

Figure 4: Percentage distribution of guidelines which respondents follow.

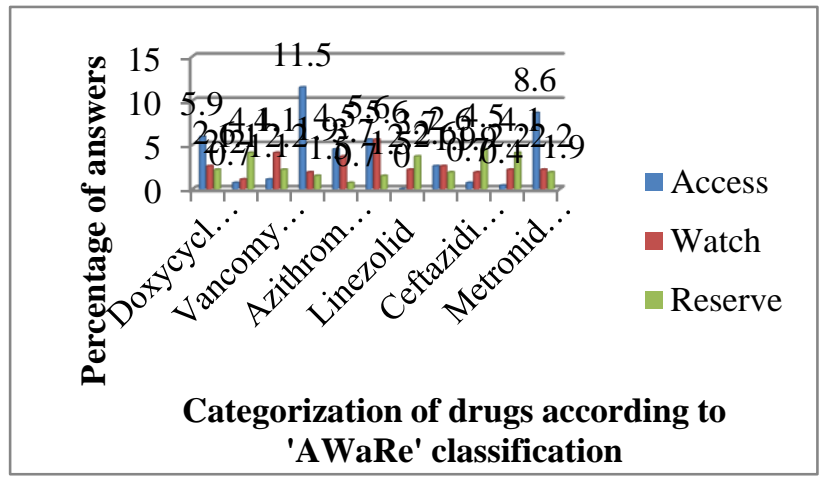

Figure 5: Percentage distribution of categorization of the drugs according to 'AWARE' classification by the respondents. 
Table 1: Frequency distribution of demographic variables of respondents.

\begin{tabular}{|ll|}
\hline Variable & $\begin{array}{c}\text { Respondents, } \\
\text { N } \%)\end{array}$ \\
\hline Gender & $186(44.8)$ \\
\hline Male & $229(55.2)$ \\
\hline Female & \\
\hline Age (years) & $233(56.1)$ \\
\hline $20-29$ & $125(30.1)$ \\
\hline $30-39$ & $44(10.6)$ \\
\hline $40-49$ & $12(2.9)$ \\
\hline $50-59$ & $1(0.2)$ \\
\hline 60 and above & \\
\hline Qualification & $86(20.7)$ \\
\hline BDS & $329(79.3)$ \\
\hline MDS & \\
\hline Specialization & $34(8.2)$ \\
\hline Orthodontics & $45(10.8)$ \\
\hline Endodontics & $15(3.6)$ \\
\hline Oral pathology & $21(5.1)$ \\
\hline Oral medicine and radiology & $38(9.2)$ \\
\hline Oral surgery & $37(8.9)$ \\
\hline Pediatric dentistry & $65(15.7)$ \\
\hline Periodontology & $70(16.9)$ \\
\hline Prosthodontics & $4(1.0)$ \\
\hline Public health dentistry & \\
\hline Practice location & $369(88.9)$ \\
\hline Urban & $41(9.9)$ \\
\hline Semi urban & $59(23.9)$ \\
\hline Rural & $51(12.3)$ \\
\hline Practice Type & $67(10.6)$ \\
\hline Private & $238(57.3)$ \\
\hline Institutional & $2(0.5)$ \\
\hline Public & $108(26.0)$ \\
\hline Mixed & \\
\hline Years of experience in the profession \\
\hline $0-5$ & $221(53.3)$ \\
\hline 6-10 & \\
\hline $11-15$ & \\
\hline Above 15 & \\
\hline Continuing dental education & \\
\hline Within last 1 year & \\
\hline Past 2-5 years & \\
\hline More than 5 years & \\
\hline & \\
\hline
\end{tabular}

\section{DISCUSSION}

The present study had a response rate was $95 \%$ which was much higher compared to study conducted by Kaul et al (38.33\%), Mohan et al (87.3\%), Kumar et al
$(87.8 \%)$, the better response rate could be attributed to personal distribution and collection of the survey responses. $^{4,10,11} 7-11 \%$ of all the antibiotics prescribed in the World originate from dental prescriptions, which although is a small percentage when compared to the same prescribed by medical practitioners, it does significantly contribute to the global consumption of antibiotics $^{12}$. The present study found that although maximum number of respondents $36.9 \%$ (153) found the need to prescribe antibiotics to only about $0-5 \%$ of the patients examined daily, there were also $25.3 \%$ (105) who prescribed antibiotics to $10-30 \%$ and $12.8 \%$ (53) who prescribed antibiotics to $30-50 \%$ of their patients daily which does contribute to antibiotic over prescription to a certain extent. James et al from their systematic review inferred that antibiotics were not useful whenever used for irreversible pulpitis especially when prescribed with the motto of pain relief. ${ }^{12,13}$ In accordance with this the present study found misuse of antibiotics to a certain extent in the form of prescription for irreversible pulpitis $5.1 \%$ (118), reversible pulpitis $1.6 \%$ (38) and also for pain relief $1.9 \%$ (44). The American dental association guidelines suggests usage of antibiotics for dental conditions should be limited to situations when there is systemic involvement due to dental causes and prescribes to perform immediate definitive and conservative dental treatment for all cases. ${ }^{14}$ With regards to this the present study found a positive outcome wherein maximum number of dentists $40.6 \%$ (288) preferred to give antibiotics for a tooth with irreversible pulpitis with pain only if there is swelling, fever and lymph node involvement. Patients who are medically compromised tend to require a prophylactic dose of antibiotics even for minor surgical procedures which run the risk of producing bacteraemia. The American academy of pediatric dentistry (AAPD) provides a set of guidelines, which intends to help the dental practitioners to make decisions regarding patients at risk with respect to antibiotic prophylaxis. This becomes essential in clinical decision making owing to the unpredictability of a susceptible patient developing an infection hence minimizing their risk of developing bacteraemia. ${ }^{12}$ With respect to this the present study found major prophylactic antibiotic prescriptions for patients with previous history of infective endocarditis, cardiac transplant after valvular damage, uncontrolled diabetes mellitus and immunecompromised patients. Patients who have undergone joint replacements in the past do not require prophylactic antibiotics prior to dental procedures. ${ }^{15,16}$ In spite of this the present study found some prescriptions for joint replacement patients and also some who prescribed for healthy patients with delayed appointment. The 2007 AHA guidelines state that an antibiotic for prophylaxis should be administered in a single dose before the procedure. ${ }^{15}$ The present study found that maximum respondents begin prophylactic prescriptions 1-3 days prior thereby contributing to over-prescription. Previous studies have shown that there was very high prevalence of self-prescription of antibiotics in rural as well as urban population in India. ${ }^{17}$ 
Table 2: Participants responses to various questions when compared with qualification.

\begin{tabular}{|c|c|c|c|c|c|}
\hline Question & Responses & $\begin{array}{l}\text { BDS } \\
\text { N }(\%)\end{array}$ & $\begin{array}{l}\text { MDS } \\
\mathbf{N}(\%)\end{array}$ & $\begin{array}{l}\text { Total } \\
\mathbf{N}(\%)\end{array}$ & $P$ value \\
\hline \multirow{5}{*}{$\begin{array}{l}\text { Q. } 1 \text { Percentage of patients examined } \\
\text { each day, that require be given } \\
\text { systemic antibiotics? }\end{array}$} & $0-5 \%$ & $21(13.7)$ & $132(86.3)$ & $153(36.9)$ & \multirow{5}{*}{$0.001 *$} \\
\hline & $5-10 \%$ & $16(18.2)$ & $72(81.8)$ & $88(21.2)$ & \\
\hline & $10-30 \%$ & $37(35.2)$ & $68(64.8)$ & $105(25.3)$ & \\
\hline & $30-50 \%$ & $12(22.6)$ & $41(77.4)$ & $53(12.8)$ & \\
\hline & $50-80 \%$ & $5(31.2)$ & $11(68.8)$ & $16(3.9)$ & \\
\hline \multirow{8}{*}{$\begin{array}{l}\text { Q. } 2 \text { What antibiotics you prefer to } \\
\text { prescribe? }\end{array}$} & Amoxicillin & $90(21.8)$ & $322(44)$ & $412(43.7)$ & \multirow{8}{*}{0.511} \\
\hline & Ciprofloxacin & $19(22.4)$ & $66(77.6)$ & $85(9)$ & \\
\hline & Metronidazole & $65(21.5)$ & $237(78.5)$ & $302(32.1)$ & \\
\hline & Doxycycline & $18(25.7)$ & $52(74.3)$ & $70(7.4)$ & \\
\hline & Azithromycin & $9(19.1)$ & $38(80.9)$ & $47(5)$ & \\
\hline & Linezolid & $1(100)$ & $0(0)$ & $1(0.1)$ & \\
\hline & Meropenem & $0(0)$ & $0(0)$ & $0(0)$ & \\
\hline & Clindamycin & $8(32)$ & $17(68)$ & $25(2.7)$ & \\
\hline \multirow{13}{*}{$\begin{array}{l}\text { Q. } 3 \text { Conditions for which you prefer } \\
\text { to give antibiotics? }\end{array}$} & $\begin{array}{l}\text { Facial swelling due to } \\
\text { dental related causes }\end{array}$ & 89 (22.2) & $311(77.8)$ & $400(17.3)$ & \multirow{13}{*}{0.436} \\
\hline & Pain relief & $14(31.8)$ & $30(68.2)$ & $44(1.9)$ & \\
\hline & Implant & $33(17.6)$ & $155(82.4)$ & $188(8.1)$ & \\
\hline & Periodontal surgeries & $52(23.7)$ & $167(76.3)$ & $219(9.5)$ & \\
\hline & Endodontic flare up & $35(16)$ & $184(84)$ & $219(9.5)$ & \\
\hline & Reversible pulpitis & $6(15.8)$ & $32(84.2)$ & $38(1.6)$ & \\
\hline & Irreversible pulpitis & $27(22.9)$ & $91(77.1)$ & $118(5.1)$ & \\
\hline & Dent alveolar abscess & $70(21.8)$ & $251(78.2)$ & $321(13.9)$ & \\
\hline & Facial cellulitis & $59(19.7)$ & $240(80.3)$ & $299(12.9)$ & \\
\hline & $\begin{array}{l}\text { Replantation after } \\
\text { avulsion }\end{array}$ & $47(17.7)$ & $218(82.3)$ & $265(11.5)$ & \\
\hline & Intrusion & $12(21.1)$ & $45(78.9)$ & $57(2.5)$ & \\
\hline & Extrusion & $14(22.2)$ & $49(77.8)$ & $63(2.7)$ & \\
\hline & Luxation/subluxation & $16(20)$ & $64(80)$ & $80(3.5)$ & \\
\hline \multirow{4}{*}{$\begin{array}{l}\text { Q. } 4 \text { Tooth no. } 16 \text { has irreversible } \\
\text { pulpitis with vital pulp confirmed by } \\
\text { the standard tests, under which } \\
\text { conditions do you prefer to give } \\
\text { antibiotics? }\end{array}$} & Pain & $5(45.5)$ & $6(54.5)$ & $11(1.5)$ & \multirow{4}{*}{$0.013^{*}$} \\
\hline & $\begin{array}{l}\text { Pain and } \\
\text { swelling }\end{array}$ & $54(27.7)$ & $141(72.3)$ & $195(27.5)$ & \\
\hline & $\begin{array}{l}\text { Pain, swelling and } \\
\text { fever }\end{array}$ & $44(22.3)$ & $153(77.7)$ & $197(27.7)$ & \\
\hline & $\begin{array}{l}\text { With pain, swelling, } \\
\text { fever and lymph node } \\
\text { involvement }\end{array}$ & $47(16.3)$ & $241(83.7)$ & $288(40.6)$ & \\
\hline \multirow{2}{*}{$\begin{array}{l}\text { Q. } 5 \text { Do you believe in use of } \\
\text { prophylactic antibiotics before } \\
\text { surgery? }\end{array}$} & Yes & $72(21.8)$ & $259(78.2)$ & $331(79.8)$ & \multirow{2}{*}{0.484} \\
\hline & No & $19(22.6)$ & $65(77.4)$ & $84(20.2)$ & \\
\hline \multirow{2}{*}{$\begin{array}{l}\text { Q. } 7 \text { Have you ever come across } \\
\text { patients who have self-prescribed } \\
\text { antibiotics? }\end{array}$} & Yes & $68(21.5)$ & $248(78.5)$ & $316(76.1)$ & \multirow{2}{*}{0.719} \\
\hline & No & $23(23.2)$ & $76(76.8)$ & 99 (23.9) & \\
\hline \multirow[t]{2}{*}{$\begin{array}{l}\text { Q. } 8 \text { Have you ever advised an } \\
\text { antibiotic sensitivity/ culture test for } \\
\text { your patients? }\end{array}$} & Yes & $29(20.6)$ & $112(79.4)$ & 141(34) & \multirow[t]{2}{*}{0.631} \\
\hline & No & $62(22.6)$ & $212(77.4)$ & $274(66)$ & \\
\hline \multirow[t]{2}{*}{$\begin{array}{l}\text { Q. } 9 \text { Have you come across patients } \\
\text { who did not respond to antibiotics? } \\
\text { (undergone resistance to antibiotics) }\end{array}$} & Yes & $44(20.7)$ & $169(79.3)$ & $213(51.3)$ & \multirow[t]{2}{*}{0.521} \\
\hline & No & $47(23.3)$ & $155(76.7)$ & $202(48.7)$ & \\
\hline
\end{tabular}




\begin{tabular}{|c|c|c|c|c|c|}
\hline Question & Responses & $\begin{array}{l}\text { BDS } \\
\text { N }(\%)\end{array}$ & $\begin{array}{l}\text { MDS } \\
\mathbf{N}(\%)\end{array}$ & $\begin{array}{l}\text { Total } \\
\mathbf{N}(\%)\end{array}$ & $P$ value \\
\hline \multirow[t]{2}{*}{$\begin{array}{l}\text { Q. 10a) Do you timely check for any } \\
\text { new guidelines or for any updates on } \\
\text { existing ones? }\end{array}$} & Yes & $36(14.8)$ & $207(82.2)$ & $243(58.6)$ & \multirow[t]{2}{*}{$0.001 *$} \\
\hline & No & $55(32)$ & $117(68)$ & $172(41.4)$ & \\
\hline \multirow[t]{2}{*}{$\begin{array}{l}\text { Q. 11a) Are you aware about the } \\
\text { 'AWaRe' classification by WHO? }\end{array}$} & Yes & $10(19.2)$ & $42(80.2)$ & $52(12.5)$ & \multirow[t]{2}{*}{0.214} \\
\hline & No & $81(23.2)$ & $282(76.8)$ & $363(87.2)$ & \\
\hline \multirow[t]{2}{*}{$\begin{array}{l}\text { Q. 12a) Are you aware about the } \\
\text { Antimicrobial Stewardship concept } \\
\text { introduced by WHO? }\end{array}$} & Yes & $7(25)$ & $21(75)$ & $28(6.7)$ & \multirow[t]{2}{*}{0.684} \\
\hline & No & $84(21.3)$ & $303(78.3)$ & 387 (93.3) & \\
\hline \multirow[t]{2}{*}{$\begin{array}{l}\text { Q.12b) Do you believe in } \\
\text { implementing the Antimicrobial } \\
\text { Stewardship concept in India? }\end{array}$} & Yes & $29(24.4)$ & 90 (75.6) & $119(28.7)$ & \multirow[t]{2}{*}{0.544} \\
\hline & No & $16(26.2)$ & $46(14.2)$ & $62(14.7)$ & \\
\hline \multirow[t]{2}{*}{$\begin{array}{l}\text { Q. } 13 \text { Do you believe that the packet } \\
\text { of antibiotics should include its } \\
\text { susceptibility towards pathogens? }\end{array}$} & Yes & 73 (21.3) & $269(78.7)$ & $342(82.4)$ & \multirow[t]{2}{*}{0.535} \\
\hline & No & $18(24.7)$ & $55(75.3)$ & 73 (17.6) & \\
\hline $\begin{array}{l}\text { Q. } 14 \text { Have you recently attended } \\
\text { any CDE programs arranged for } \\
\text { antibiotic abuse or antibiotic } \\
\text { resistance? }\end{array}$ & Yes & $16(21.3)$ & $59(78.7)$ & $75(18.1)$ & \multirow[t]{2}{*}{0.891} \\
\hline & No & $75(22.1)$ & $265(77.9)$ & $340(81.9)$ & \\
\hline
\end{tabular}

Similarly, the present study also found a significant number of dentists who came across patients who selfprescribed antibiotics $76.1 \%$ (316) and also a significant number who came across patients who did not respond to antibiotics $51.3 \%$ (213) which hints that we need to focus on antibiotic sensitivity/culture tests. Rarely the dentist faces the challenge of combating a resistant strain of bacteria which would not relent to prescription of routine antibiotics, such situations demand the use of antibiotic sensitivity test to identify and single out exactly which antibiotic is suitable for that particular strain of bacteria. Antibiotic sensitivity test requires a sample to be obtained from the lesion which could be the exudates or purulent material or an excised granuloma or cyst sent to the diagnostic lab where the histopathology can also be done for the lesion. ${ }^{18}$ A study conducted by Singh et al found that less than $40 \%$ of the dentists advised culture sensitivity test, which is very similar to the results found in the present study $34 \%$ (141). ${ }^{19}$

The WHO has introduced the concept of antimicrobial stewardship (AMS) to make sure that the health sector as a whole starts taking responsibility for the health and well being of the population and also guides the health systems first nationally and eventually globally. AMS is one of the three pillars which are aimed at strengthening the health systems at large. Infection prevention and control (IPC) and medicine and patient safety are the other two pillars of the tripod. AMS helps in controlling the antimicrobial resistance when applied in conjunction with antibiotic use surveillance, the WHO essential medicines list (EML) and AWaRe classification (access, watch, reserve). ${ }^{5}$ The present study clearly reflected that $93.3 \%$ (387) dentists were unaware about the antimicrobial stewardship concept. This study also found that $87.2 \%$ (363) dentists were not aware about this classification which led to very few dentists who could correctly categorize the drugs in the question that followed. One of the reasons for the above situation could be that maximum number of dentists in this study $81.9 \%$ (340) had not attended any continuing education programs or events specifically for antimicrobial resistance which was found to be more than that observed by Naveen et al $(64 \%) .{ }^{12}$ India's National action plan (NAP) for antimicrobial resistance (AMR) was released in April 2017 by the union ministry of health and family welfare. $^{20}$ Antimicrobial stewardship can be started at hospital/clinical level to curb the overuse of antibiotics and outpatient antibiotic stewardship can be established..$^{21-23}$

\section{CONCLUSION}

There is a rising concern for antibiotic resistance worldwide, the primary cause of which is overuse and misuse, both of which are clearly evidenced in the present study to a certain extent. Hence, there is an urgent need to focus on building guidelines that specify all the possible dental conditions which require antibiotic prescription in accordance with the WHO essential medicine list (EML), AWaRe classification in order to completely curb antibiotic over prescription by dentists. Outpatient 
Antimicrobial Stewardship can be established and dental practitioners should be trained for the same. Dental practitioners should be updated on recent guidelines for the use of antibiotics with the help of Continuing Education programs. Moreover, on coming across patients who self-prescribe antibiotics, dentists should warn them about its ill effects and at the same time focus on identifying traits of antibiotic resistance among their patients and advice sensitivity/culture tests for the same.

\section{ACKNOWLEDGEMENTS}

Authors would like to thank all the survey participants.

Funding: No funding sources

Conflict of interest: None declared

Ethical approval: The study was approved by the Institutional Ethics Committee

\section{REFERENCES}

1. Interagency coordination group on antimicrobial resistance no time to wait: securing the future from drug-resistant infections report to the secretarygeneral of the United Nations. Available at: https://www.who.int/antimicrobial-resistance/ interagency-coordination-group/IACG_final_report_ EN.pdf?ua=1. Accessed on 22 November 2019.

2. American dental association council on scientific affairs. Combating antibiotic resistance. J Am Dent Assoc. 2004;135(4):484-7.

3. Agnihotry A, Gill KS, Stevenson IRG, Fedorowicz Z, Kumar V, Sprakel J, et al. Irreversible pulpitis - a source of antibiotic over-prescription?. Braz Dent J. 2019;30(4),374-9.

4. Kaul R, Angrish P, Jain P, Saha S, Sengupta A, Mukherjee S. A survey on the use of antibiotics among the dentists of Kolkata, West Bengal, India. Int J Clin Pediatr Dent. 2018;11(2):122-7.

5. World health organization, antimicrobial stewardship programmes in health-care facilities in low- and middle-income countries: a WHO practical toolkit (2019). Available at:https://apps.who.int/iris/handle/ 10665/329404. Accessed on 20 August 2020.

6. World health organization, global action plan on antimicrobial resistance (2015). Available at: https://apps.who.int/iris/handle/10665/193736.

Accessed on 20 August 2020.

7. Dyar OJ, Huttner B, Schouten J, Pulcini C. ESCMID study group for antimicrobial stewardship: What is antimicrobial stewardship?. Clin Microbiol Infect. 2017;23(11):793-8.

8. Centers for disease control and prevention, antibiotic resistance a global threat. Available at: https://www.cdc.gov/drugresistance/solutionsinitiative/stories/ar-global-threat.html. Accessed on 20 August 2020.

9. Mohan S, Thakur J. A questionnaire based survey on the antibiotic prescription pattern of dentists in eastern part of India. Int $\mathrm{J}$ Contemp Med Res. 2019;6(4):D16-9.

10. Gorstein J, Sullivan KM, Parvanta I, Begin F. Indicators and methods for cross-sectional surveys of vitamin and mineral status of populations. Available at: https://www.who.int/vmnis/toolkit/mcnmicronutrient-surveys.pdf. Accessed on 20 August 2020.

11. Kumar KP, Kaushik M, Kumar PU, Reddy MS, Prashar N. Antibiotic prescribing habits of dental surgeons in hyderabad city, India, for pulpal and periapical pathologies: a survey. Adv Pharmacol Sci. 2013;2013:537385.

12. Naveen N, Guru SP, Vanishree N, Patnaik S, Bharath C, Keerthi PKS, et al. Current trends in prescription of antibiotics among dentists working in various dental colleges of Bangalore city, India- a cross sectional study. Int J Oral Health Med Res. 2015;2(2):8-14.

13. Keenan JV, Farman AG, Fedorowicz Z, Newton JT. A cochrane systematic review finds no evidence to support the use of antibiotics for pain relief in irreversible pulpitis. J Endod. 2006;32(2):87-92.

14. Lockhart PB, Tampi MP, Abt E, Aminoshariae A, Durkin M, Fouad A, et al. Evidence based clinical practice guideline on antibiotic use for the urgent management of pulpal and periapical-related dental pain and intraoral swelling: A report from the American dental association. J Am Dent Assoc. 2019;150(11):906-21.

15. American association of endodontists, AAE quick reference guide on antibiotic prophylaxis 2017 update. Available at: https://www.aae.org/ specialty/wp-content/uploads/sites/2/2017/06/ aae_antibiotic-prophylaxis-2017update.pdf. Accessed on 20 August 2020.

16. Sollecito TP, Abt E, Lockhart PB, Edmund T, Thomas P, Sharon T, et al. The use of prophylactic antibiotics prior to dental procedures in patients with prosthetic joints: Evidence-based clinical practice guideline for dental practitioners-a report of the American dental association council on scientific affairs. J Am Dent Assoc. 2015;146(1):11-6.

17. Dineshkumar B, Raghuram TC, Radhaiah G, Krishnaswamy K. Profile of drug use in urban and rural India. Pharmacoeconomics. 1995;7(4):332-46.

18. Larato DC. The antibiotic sensitivity test in dental practice. Oral Surg Oral Med Oral Pathol. 1966;22 (5):682-7.

19. Singh DP, Sampath N, Mahuli AV, Yadav H, Mahuli SA, Yadav R. Knowledge regarding antibiotic drug action and prescription practices among dentist in Jaipur city, Rajasthan. J Dent Res Rev. 2015;2:127-9.

20. Ranjalkar J, Chandy SJ. India's National action plan for antimicrobial resistance - an overview of the context, status, and way ahead. J Family Med Prim Care. 2019;8:1828-34. 
21. Sanchez GV, Fleming-Dutra KE, Roberts RM, Hicks LA. Core elements of outpatient antibiotic stewardship. MMWR Recomm Rep. 2016;65:1-12.

22. Gross AE, Hanna D, Rowan SA, Bleasdale SC, Suda KJ. Successful implementation of an antibiotic stewardship program in an academic dental practice. Open Forum Infect Dis. 2019;6(3):ofz067.
23. Bennadi D. Antimicrobial stewardship - an alarming call in dentistry. Int J Pharm Pharm Sci. 2014;6:46-9.

Cite this article as: Parekh AN, Balasubramanian K, Bhate P, Kalra DD. Antibiotics usage, how well we know it? KAP survey among the dentist population in Mumbai. Int J Basic Clin Pharmacol 2020;9:1713-20. 